\title{
A "identidade da CPLP no domínio da defesa": uma visão ampliada para a cooperação em defesa
}

\author{
The "identity of the CPLP in the field of defence": \\ an enlarged vision for cooperation in defence
}

Rev. Bras. Est. Def. v. 6, nº 2, jul./dez. 2019, p. 205-231

DOI: 10.26792/RBED.v6n2.2019.75171

ISSN 2358-3932

\section{KAMILLA RAQUEL RIZZI \\ LUÍS MANUEL BRÁS BERNARDINO}

\section{INTRODUÇÃO}

Uma das primeiras ideias sobre o que é e o que representa no atual sistema mundial a Comunidade dos Países de Língua Portuguesa (CPLP) é a de ser uma organização internacional baseada na partilha de uma matriz comum histórico-cultural-linguística, que aposta no desenvolvimento da cultura e da língua portuguesa, e que vem afirmando-se no mundo por meio da adoção de uma inovadora e pragmática visão político-estratégica. Essa visão, concretamente na área da Defesa, torna-se mais evidente nos seguintes conceitos: mares/oceanos; geopolítica/geoestratégia; e cooperação/concertação, pois a partilha de experiências e a comunhão de afetos sempre norteou os destinos e os objetivos da organização.

A presente pesquisa tem por objetivo geral analisar o significado da cooperação estratégica e seu impacto na organização, buscando compreender a importância da Comunidade para seus países, evidenciando essa visão na cooperação de Defesa. Especificamente, pretende-se evidenciar quais ações estão sendo postas em prática para tornar a cooperação bilateral do passado na cooperação multilateral do presente e refletir sobre a ne-

\footnotetext{
Kamilla Raquel Rizzi - Professora Associada I de Relações Internacionais da Universidade Federal do Pampa, campus Santana do Livramento. Doutora em Ciência Política e Mestre em Relações Internacionais/UFRGS. Pesquisadora do NERINT-UFRGS, CebAFRICA-UFRGS e GeAFRICAUNIPAMPA.

Luís Manuel Brás Bernardino - Doutor em Relações Internacionais pela Universidade de Lisboa. Investigador Doutorado do Centro de Estudos Internacionais da Universidade de Lisboa (CEI-IUL). Tenente-Coronel de Infantaria das Forças Armadas Portuguesas habilitado com o Curso de EstadoMaior. Atualmente desempenha funções de Portuguese Senior National Representative (SNR) no NATO Joint Force Command Brunssum (JFCBS) na Holanda.
} 
cessidade de ter na Comunidade uma cooperação bi-multilateral para o futuro na cooperação de Defesa. Assim, procura-se ponderar em relação ao seguinte problema de pesquisa: quais as motivações dessa visão geoestratégica da CPLP que resultaram no documento intitulado "Identidade da CPLP no Domínio da Defesa”? Como hipótese inicial, compreende-se que a Comunidade tem como base estatutária a concertação político-diplomática e a cooperação entre seus membros, fato que os aproxima e legitima a própria Comunidade, sendo a motivação essencial de sua existência e ampliação. $\mathrm{O}$ avanço da cooperação na área de Defesa complementa essa ideia-base da organização, ao fortalecer a dimensão estratégica desta no atual sistema mundial, essencialmente em torno dos três conceitos-chave supracitados.

Metodologicamente, a pesquisa utiliza a abordagem qualitativa pois, de acordo com Minayo (1994), procura responder a questões particulares, preocupando-se, nas Ciências Sociais, com um nível de realidade que não pode ser quantificado, trabalhando com o universo de significados, valores e atitudes, o que corresponde a um espaço mais denso das relações, processos e fenômenos que não podem ser reduzidos à análise de variáveis. Quanto ao método hipotético-dedutivo utilizado, a partir da observação dos fatos e eventos apontados, se elaborou o problema de pesquisa, com sua explicação pela formulação de hipóteses e destas, deduzem-se consequências que deverão ser testadas ou falseadas. “[...] Quando não se consegue derrubar a hipótese, tem-se sua corroboração; segundo Popper, a hipótese se mostra válida, pois superou todos os testes, porém ela não é definitivamente confirmada, pois a qualquer momento poderá surgir um fato que a invalide [...]" (Gerhardt and Silveira 2009, 27). Classifica-se essa pesquisa, ainda, como descritivo-explicativa em relação aos seus objetivos de pesquisa, e quanto aos procedimentos técnicos, utilizou-se a revisão bibliográfica e análise documental de fontes primárias, secundárias e de imprensa.

\section{O MAR COMO ELEMENTO GEOESTRATÉGICO DE AFIRMAÇÃO NA COMUNIDADE}

O mar é um elemento permanente da geografia de todos os Estadosmembros da Comunidade. Foi pelo mar que os navegadores portugueses dos séculos XV e XVI procuraram os acessos possíveis aos continentes africano e americano. Essa ligação tornou-se permanente no aspecto comercial e científico-cultural, com implicações socioeconômicas, políticas e humanas, em que Estados com continuidades histórico-culturais e linguísticas se edificaram, aproximando povos originariamente de diferentes credos e culturas. Foi ainda por meio do mar, até a metade do século XX, que 
a amálgama de povos em diferentes continentes e sob a mesma bandeira e a mesma língua, forjaram identidades, agregando-as, trocando experiências valorativas (tanto as positivas como as negativas durante o domínio colonial), clarificaram interesses e proporcionaram, já no final da última década do mesmo século, o entendimento solidário e de cooperação que abriria o caminho para a edificação de uma identidade coletiva, supranacional, tão específica como a CPLP.

Conforme Rizzi (2014), o primeiro esforço coletivo para a criação da comunidade lusófona ocorreu em novembro de 1989, em São Luís (Maranhão, Brasil), quando o Presidente José Sarney reuniu os Chefes de Estado e de Governo de Cabo Verde, Guiné-Bissau, Moçambique, Portugal e de São Tomé e Príncipe, além do Representante Especial do Presidente da República de Angola, pois naquela ocasião,

[...] foi criado o Instituto Internacional da Língua Portuguesa (IILP), cujos objetivos seriam o de defender e promover o idioma; enriquecer a língua como veículo de cultura, educação, informação e de acesso ao conhecimento científico e tecnológico; desenvolver as relações culturais entre os lusófonos; incentivar a cooperação, pesquisa e intercâmbio nos domínios da língua e da cultura; e difundir o Acordo Ortográfico (Rizzi 2014, 150).

Não é demasiado lembrar que a Comunidade foi criada por uma decisão de Estados soberanos, e surgiu praticamente duas décadas depois do processo que levou à independência das ex-colônias portuguesas na África, desenhando-se — independentemente das continuidades e descontinuidades históricas - uma comunidade lusófona que, apesar de não integrar todo o universo da lusofonia, orienta-se para uma inserção global com matrizes culturais, históricas e de afetos comuns, porém, por vezes, com interesses e objetivos diversos. O Brasil estava na primeira década de sua Redemocratização política e Portugal avançava na estabilidade da sua Terceira República, ambos buscando se (re)aproximar dos Países Africanos de Língua Oficial Portuguesa (Palop).

Nesse aspecto, cabe ressaltar que é interessante, na constituição da Comunidade, a parceria Brasil-Portugal, a base das relações intra-CPLP ainda hoje e em todos os setores de cooperação. Na década de 1990, ocorreu uma diminuição de contatos do Brasil com o outro lado do Atlântico Sul, ao mesmo tempo em que em Brasília se “[...] suspeitava das ações portuguesas no vácuo de poder e influência deixada nos cinco Palop [...]” (Rizzi 2014, 147), como fica evidente:

O Governo português - a quem efetivamente interessa retomar sua presença nos Palop — reconhece ao Brasil papel protagônico 
dentro da comunidade lusófona, por suas iniciativas pioneiras de reconhecimento político, por seu envolvimento na cooperação técnica e formação de recursos humanos e por seus investimentos econômicos de vulto, em determinados países da Comunidade.

Por outro lado, o crédito político e a confiabilidade conquistados pelo governo brasileiro junto aos Palop não se traduzem numa capacidade econômica crescente e sustentada, que permita aprofundar e alicerçar a presença brasileira nesses países [...]. Assim, como atende ao interesse nacional português associar-se com o Brasil para, através de nossa influência política, voltar a ter uma presença em África, também atende ao interesse nacional brasileiro utilizar o conhecimento aprofundado que tem Portugal da região e dos recursos [...] que é capaz de mobilizar (Brasemb Praia, OF C no 00122, 1990, 1, apud Rizzi 2014, 147. Grifo nosso).

Com as reformas políticas e econômicas nos cinco Palop no início da década de 1990, Lisboa buscou reacender essas relações bilaterais, pois foram afastados do poder em Cabo Verde, Guiné-Bissau e São Tomé e Príncipe os dirigentes que se tornaram inimigos de Portugal durante os respectivos processos de independência. Gradualmente, esses eventos abriram possibilidade para um relacionamento diferenciado entre "Lisboa de um lado, e Praia e São Tomé de outro, esperando que Bissau, Maputo e Luanda, ao trilharem a senda democrática, sigam essa nova tendência iniciada por Cabo Verde" (Alvaro 1993, 6-7, apud Rizzi 2014, 147-8). Essa mudança no contexto econômico e político nos Palop fez com que

Portugal [desejasse] aproveitar esse novo capítulo da história. A sua presença nas antigas colônias da África constitui, hoje, uma das principais metas da sua política externa. Está atuante no domínio do comércio, ativo no terreno da cooperação técnica e aberto da colaboração com os novos governos democráticos de Cabo Verde e de São Tomé e Príncipe, enquanto aguarda ansiosamente (mas com decidida participação) o desfecho dos processos de negociação entre as partes beligerantes em Angola e Moçambique [...] A ação de Lisboa junto aos Países Africanos de Língua Oficial Portuguesa manifesta-se, assim, em vários domínios. Comprova isso a sua preocupação com a crescente influência do idioma francês em Guiné-Bissau e da presença da África do Sul em Moçambique (Alvaro 1993, 7-8, apud Rizzi 2014, 148).

Nesses termos, o retorno português para os Palop foi um importante impulso para a concretização da CPLP, bem como o interesse brasileiro em manter a presença conquistada naqueles países, anteriormente, também 
o era. Desde a criação do IILP (1989), o apoio de Lisboa foi irrestrito, pois se identificavam as possibilidades que a Comunidade efetivaria na sua relação com as antigas colônias, seja na África, seja na América do Sul. O embaixador brasileiro em Praia, que vislumbrava a visão portuguesa da CPLP como uma "uma fusão do atual (sic) esquema 5 mais 1 (Portugal mais Palop) e a sua adaptação à entrada do Brasil, no contex to mais amplo da comunidade que abarcaria os sete" (Alvaro 1993, 9, apud Rizzi 2014, 148). O destino da instituição estava sob direção brasileira, pois

[A] instituição da Comunidade dos Países de Língua Portuguesa, tal como concebida, poderá vir a ser um instrumento de ação política valioso, mas devemos avançar com a percepção realista de que no seio da Comunidade poderá instalar-se a mesma rivalidade que hoje se observa na "Francophonie", onde França e Canadá trocam farpas em disputa pela liderança do movimento, se bem que por razões distintas. [...] A França (leia-se, na questão em tela, Portugal), por ser o berço da língua e da cultura francesas, o Canadá (leia-se, na questão em tela, o Brasil), país rico e industrializado. Mutatis mutandis, o Brasil exerce atração nos Palop, por se tratar de um país de origem comum à deles, mas sobretudo por ter conseguido desenvolver-se e ostentar um parque industrial que Portugal não pode sequer pensar em igualar (Alvaro 1993, 11, apud Rizzi 2014, 148. Grifo nosso).

Logo, as relações Brasília-Lisboa, constituídas historicamente entre a aproximação e a distância, caracterizaram também o tom e as etapas de implantação da própria CPLP. Nesse sentido, os dois países "por motivos iguais, mas em seus respectivos contextos e interesses locais-regionais-internacionais (influência política e contatos econômicos baseados na história e cultura em comum)" (Rizzi 2014, 150) uniram esforços para a concretização da Comunidade, pois "ficou acertado que o Brasil e Portugal buscariam ações de cooperação conjunta nos Palop como forma de testar a viabilidade de um trabalho comum em todo o continente" (Brasemb Praia 1992, apud Rizzi 2014, 148). Para Rizzi (2014), o ponto de divergência entre Brasília e Lisboa, relativo à Comunidade, referia-se ao formato dessa cooperação: Portugal identificava a relação Portugal-Brasil nos Palop, na "equação $2+5=7$ ", como a "ideal":

A documentação diplomática é rica nesse sentido, pois clarifica o entendimento que o Brasil tinha da parceria multilateral (com a criação do IILP e depois a CPLP), como "equação $7=7$ ", mais "dinâmica e positiva". O que prevaleceu, no entendimento da presente pesquisa, foi o posicionamento brasileiro, que efetivou a Comunidade Lusófona a partir de um teor cultural, mas com claros tons políticos e econômi$\cos$ (Rizzi 2014, 149). 
Em 1994, reuniram-se em Brasília os Ministros das Relações Exteriores e Negócios Estrangeiros dos sete países fundadores da CPLP, por iniciativa do Presidente Itamar Franco. O encontro resultou na recomendação a seus Chefes de Estado da realização de um encontro com o intuito de elaborar o ato constitutivo da Comunidade, além de estabelecer o Grupo de Concertação Permanente (com sede em Lisboa), a ser integrado pelo Diretor-Geral da Política Externa do Ministério dos Negócios Estrangeiros de Portugal e pelos Embaixadores dos demais seis países, creditados na capital portuguesa. Em junho de 1995, em Lisboa, definiuse o arcabouço político e institucional da CPLP. O Grupo de Ministros de Relações Exteriores e Negócios Estrangeiros passou a ser denominado “Comitê de Concertação Permanente" e recomendou também a previsão de abril de 1996 para a realização da Cimeira constitutiva da Comunidade. Em 17 de julho de 1996, também em Lisboa, os Chefes de Estado e de Governo dos sete países-membros assinaram a Declaração Constitutiva da Comunidade dos Países de Língua Portuguesa. ${ }^{1}$ Em maio de 2002, com a conquista de sua independência, o Timor-Leste tornou-se o oitavo país membro da Comunidade. Em julho de 2014, após um processo longo e polêmico de adesão aos critérios organizativos, a Guiné Equatorial também tornou-se Estado-membro da organização, perfazendo os atuais 9 Estados-membros.

$\mathrm{Na}$ Declaração Constitutiva, os objetivos político-econômicos e diplomáticos estavam em paralelo aos culturais, no processo de criação da CPLP. Para Rizzi (2014), essa constatação pode ser verificada pela enumeração dos principais objetivos da Comunidade, no Artigo $3^{\circ}$ de seus Estatutos (revisados em São Tomé/2001 e Brasília/2002).

Art. $3^{\circ}$. [...] a) A concertação político-diplomática entre os seus membros em matéria de relações internacionais, nomeadamente para o reforço da sua presença nos fóruns internacionais; b) A cooperação em todos os domínios, inclusive os da educação, saúde, ciência e tecnologia, defesa, agricultura, administração pública, comunicações, justiça, segurança pública, cultura, desporto e comunicação social; c) A materialização de projetos de promoção e difusão da Língua Portuguesa, designadamente através do Instituto Internacional de Língua Portuguesa (CPLP 2007, s/p. Grifo nosso).

Como vetor identitário, a CPLP é essencialmente uma comunidade na qual o mar tem uma importância inegável pluridimensional e multidisciplinar. E esse vetor une-se aos fatores estruturantes da língua e da história comuns, bem como da gestão da sua preservação e sustentabilidade. No século XXI, adicionalmente, tem ocorrido a progressiva revalorização 
das dimensões geopolíticas e geoestratégicas dos mares e oceanos. Logo, é assim a CPLP: uma comunidade de países marítimos que se espalha por quatro continentes, três oceanos, ligando mais de 250 milhões de pessoas vivendo em cerca de 10,6 milhões de $\mathrm{km}^{2}$ e usufruindo de 7,6 milhões de $\mathrm{km}^{2}$ de área marítima (sendo $120 \mathrm{Mn}$ de Zona Contíguas - Brasil, Angola, Portugal, Cabo Verde, Guiné Bissau e Timor-Leste - e $400 \mathrm{Mn}$ de Plataformas Continentais ${ }^{2}$ (Brasil e Portugal).

Neste contexto, o Oceano Atlântico merece especial destaque, levando Adriano Moreira, um dos percursores da Comunidade, a apelidá-lo de “Oceano Moreno" (1993, 239-51), pois trata-se, por excelência, de um largo corredor marítimo, cuja importância recrudesceu nas últimas décadas, por razões geopolíticas e energéticas, unindo historicamente os hemisférios sul e norte do globo, abrindo uma janela de oportunidades para que o espaço da lusofonia e da CPLP se afirmasse como exemplo de cooperação construtiva e de desenvolvimento interdependente.

Ao mesmo tempo, desenvolveu-se uma estratégia securitária em benefício dos Estados-membros, pois o desenvolvimento e a segurança estão intimamente ligados. É também efetivamente neste espaço que se localiza a esmagadora maioria dos países da CPLP: ${ }^{3}$ especificamente é no Atlântico Sul que se situam dois terços dos países que a constituem, seis dos nove Estados-membros são países lindeiros do Atlântico Sul, o que confere à Comunidade um enorme valor acrescentado no que diz respeito a recursos energéticos e às potencialidades estratégicas daí provenientes.

Na verdade, considerada a bacia do Atlântico Sul, abarcando dois continentes mesclados nas suas culturas e histórias, verifica-se ainda que o português é a língua-base de Brasil, Angola, Cabo Verde, Guiné-Bissau e São Tomé e Príncipe - o que tem levado outros países com adesão plena à organização ou como observadores associados a procurar desenvolver uma estratégia nesse sentido de introduzir a língua como idioma oficial. Sendo a CPLP uma comunidade do mar, Mongiardim (2014) analisa que o vetor da maritimidade é o elemento que mais favorece o aprofundamento das relações intracomunidade, conferindo maior grau de convergência de interesses e influindo sobre as relações de poder entre seus membros, podendo-se afirmar que esta lógica acarreta implicações sobre o equilíbrio interno da organização, constando Lisboa, Brasília e Luanda como eixo basilar, que tende a competir em alguns setores com o eixo Brasília, Luanda, Praia, Bissau, Maputo e São Tomé.

$\mathrm{E}$, adicionalmente, é importante destacar que as complexidades e desafios securitários globais - que são marca da atual conjuntura internacional pós-Guerra Fria — refletem-se no crime organizado — designadamente a pirataria, o tráfico de substâncias psicotrópicas e de pessoas, os 
conflitos regionais - e merece a atenção e a preocupação dos países da CPLP, não só pela constatação da necessidade de desenvolverem capacidades de proteção, vigilância e de segurança marítimas, mas também pelo fato de que os elementos e instrumentos securitários são matéria de uma vasta e incontornável cooperação bi e multilateral que traduz a interdependência da circunstância global e o acervo de uma colaboração que deve ser aprofundada.

Logo, a ampliação das áreas de cooperação da Comunidade, em 2002, na IV Conferência de Chefes de Estado e Governo da CPLP em Brasília, com a revisão do Estatuto da CPLP (Artigo 4, alínea “b”), justifica-se em si mesma pela conjuntura mundial. Ampliaram-se as áreas de cooperação de cinco $^{4}$ para doze,${ }^{5}$ adicionando o domínio da Defesa como uma dessas. A ampliação dos setores de cooperação indica a consolidação e o aprofundamento do intercâmbio entre os Estados-membros da Comunidade. Ademais, o incremento conferiu um amparo institucional para iniciativas que já estavam sendo desenvolvidas, mas não eram comtempladas pelos documentos oficiais. Como fica claro no Protocolo de Cooperação da CPLP no Domínio da Defesa, de 2006:

[…] É no Atlântico Sul que se situa a maioria dos Estados Membros da CPLP. Este espaço geográfico conta com importantes recursos energéticos em ambas as margens, mas também com diversos desafios de natureza securitária relacionados com o crime organizado transnacional, a pirataria ou os conflitos regionais, merecendo por isso especial atenção dos países da CPLP […]. (CPLP 2006, 4).

Com efeito, o valor e o potencial do mar são hoje, mais do que nunca, equacionados perante o binômio do desenvolvimento/segurança dos Estados. Sabe-se que, além dos 50\% das recentes descobertas de recursos energéticos da última década e que se encontram em áreas de influência geográfica de países da Comunidade, urge que cada Estado-membro desenvolva capacidades no setor da segurança marítima com impacto para a proteção das suas zonas econômicas exclusivas e das suas plataformas continentais, bem como nas áreas de busca e salvamento e que já se encontram sob a responsabilidade designadamente de Portugal e do Brasil. Concordase, aqui, com Azevedo (2014), pois:

[...] a CPLP, na sua relação com o Oceano Atlântico, impele-nos a compreender não apenas a importância geoestratégica das duas margens (africana e sul-americana), mas, sobretudo, reconhecer um triângulo estratégico no quadro da CPLP e avaliar a medida de outros interesses que concorrem na região para que se percebam claramente quais as potencialidades deste mar oceano e que tipo de cooperação se pretende a médio e longo prazo. É evidente que, num mundo em mudança acelerada, 
a concentração regional alcança um peso de tal forma decisivo que influi na geopolítica e determina uma estratégia de dinâmicas sujeitas a constantes adaptações (Azevedo 2014, 21. Grifo nosso).

No caso do Atlântico Sul, atenta-se às ameaças transnacionais e aos focos de instabilidade da região do Golfo da Guiné (com destaque para a pirataria, o tráfico de pessoas e estupefacientes, os fluxos migratórios ilegais, o tráfico de armas), bem como o respetivo impacto nas populações locais. A nova geopolítica dos recursos energéticos do século XXI alcança uma importância tal que induz a uma nova concertação das seguranças marítimas nacionais. Convém não esquecer que as ameaças no mar têm origem em terra e não no mar, o que obriga a um reforço da cooperação no domínio da segurança e da defesa no seio da Comunidade.

A segurança marítima é, pois, um fator estratégico de desenvolvimento e com maior acuidade no Atlântico Sul. Os conflitos em determinados Estados africanos têm levado a comunidade internacional a implementar mecanismos de apoio ao desenvolvimento e segurança que levam a intervenções de diversas formas, quase sempre sob mandato da Organização das Nações Unidas (ONU), da União Europeia (UE) e da própria Organização do Tratado do Atlântico Norte (OTAN), cada vez mais " $[\ldots .$.$] com maior$ frequência e intensidade [...]” (Bernardino 2011, 46).

A CPLP como comunidade marítima necessita de uma gestão sustentada dos seus recursos - aspecto que não tem sido desvalorizado pela organização, mas cuja evolução e progresso na presente conjuntura se tornam prementes a agilizar. Não é demais recordar que, em 2007, o Conselho de Ministros da Comunidade determinou que a concertação de esforços entre os países da Comunidade no sentido da “[ [...] elaboração de uma visão integrada, com vista a promover o desenvolvimento sustentável dos espaços oceânicos sob as suas respectivas jurisdições nacionais, inclusive por meio da cooperação internacional [...]” (Bernardino 2011, 46) fosse devidamente refletida e implementada. Estavam, pois, lançadas as bases da designada "Estratégia da CPLP para os Oceanos".

Partindo do pressuposto de que os Estados-membros da Comunidade já não eram alheios à importância da adesão à Convenção das Nações Unidas sobre o Direito do Mar, a Estratégia da CPLP para os Oceanos, ao basear-se nas políticas nacionais dos Estados membros, teve um objetivo comum de partilha e união, e também de tomada de consciência sobre a diversidade das realidades de cada país quanto aos níveis de desenvolvimento, bem como aos aspectos relacionados à caracterização das respetivas inserções geográficas. Assinado em Lisboa, em março de 2010, pelos Ministros da Defesa (e/ou Mar), aquele documento reflete ainda hoje a 
ferramenta mais importante para a cooperação multilateral integrada, na medida em que tem o mar por objeto e também por instrumento, com base no conceito de desenvolvimento sustentável e da correta gestão dos recursos marinhos.

Assim, compreende-se que a Estratégia para os Oceanos demonstra a tipificação das ações de cooperação, interdependência e interoperabilidade nos mais diversos segmentos, bem como o caráter multidisciplinar de intervenção e, ao mesmo tempo, um sentido de partilha e repartição de tarefas a serem cumpridas pelos Estados-membros, incluída a cooperação no domínio da Defesa. Sendo a cooperação o eixo central de toda a organização das ações da Comunidade, ela está presente em todas as suas vertentes e constitui o vértice em função do qual se move toda a organização. É neste vértice que se assenta a análise conjuntural e prospetiva dos paradigmas e desafios globais, funcionando como elemento-motor da interatividade e do juízo assertivo na implementação de estratégias e programas de cooperação. Sublinha-se, por isso, a pertinência e o caráter originário da cooperação em geral no âmbito da Comunidade e o seu contributo para a formulação de doutrinas e implementação de iniciativas de interesse comum para os Estados-membros.

A cooperação da CPLP no domínio da Defesa é, assim, um subsistema da cooperação geral da Comunidade. Com base na recomendação dos Ministros da Defesa de Portugal e dos Palop, de julho de 1998, iniciaramse as atividades neste componente, tendo o Brasil ainda, numa primeira fase, mantido o caráter de Observador, assumindo como membro de pleno direito três anos mais tarde. Com efeito, os ministros estavam então conscientes do valor e importância que a Cooperação Técnico-Militar (CTM) portuguesa possuía, a nível bilateral, com os Palop e que no entendimento comum e, ao mais alto nível, foi considerada a "vertente primordial da relação fraterna que" vinha se "renovando e fortalecendo entre os respetivos países e as suas Forças Armadas”. Nesse sentido, “decidiram enveredar por uma nova fase desta cooperação, alargando-a, em determinados domínios, a um novo conceito de globalização". Nascia assim o conceito de "Globalização da Cooperação Técnico-Militar".

Em 1998, o início da instabilidade na Guiné-Bissau levou à criação do Grupo de Contato, reunindo os Ministros dos Negócios Estrangeiros e das Relações Exteriores na CPLP para, por meio das vias diplomáticas, encerrar o conflito civil.

A Comunidade adotou a diplomacia preventiva para a gestão de crises internas na África. Assim, a organização buscou importantes aliados no continente, como a Organização da Unidade Africana (OUA) e a Comunidade Econômica dos Estados da África Ocidental (CEDEAO), no sentido de 
obter maior aproximação e integração com as Organizações Regionais Africanas (Bernardino and Leal 2011). A credibilidade obtida resultou no avanço da visibilidade internacional sobre a atuação da CPLP na temática "diplomacia para paz", representando um importante marco nos assuntos de segurança e defesa (Bernardino and Leal 2011). Em 1999, a Comunidade compôs a primeira Missão de Observação Eleitoral para acompanhar o referendo sobre a autodeterminação de Timor-Leste em 1999.

A Comunidade, desde então, tem demonstrado vocação e maturidade institucional para as Missões de Mediação e as Missões de Observação Eleitoral da CPLP (MOE-CPLP) ${ }^{8}$ - embora a intervenção da Comunidade nas crises de São Tomé e Príncipe (2003) e mais concretamente na crise de Guiné-Bissau (2012) tenha ficado aquém das expectativas, pois “[ [...] the consolidation of the CPLP as an effective inter-governmental organization (IGO) via the Guiné crisis was therefore important to Portugal as broad engagement with Africa as well as for the CPLP as an institution […]” (MacQueen 2003, 2).

Em 2004, durante a reunião do Conselho de Segurança das Nações Unidas, a CPLP foi chamada a se pronunciar a respeito do Relatório Especial do Secretário-Geral sobre a Missão da ONU de Apoio a TimorLeste. Para Bernardino (2008), além de representar um marco para a Comunidade (uma espécie de batismo de fogo na área de defesa e segurança regionais), essa Missão possibilitou o início de amplos diálogos multilaterais da organização a nível global. Com os resultados relativamente positivos na Guiné-Bissau e em Timor-Leste, durante a III Conferência de Chefes de Estado e de Governo, em Maputo, em 2000, foi assinada a "Declaração Conjunta sobre Cooperação, Desenvolvimento e Democracia na Era da Globalização”, o primeiro documento a fazer referência à cooperação na área de segurança e defesa, o qual traça mecanismos de cooperação e dentre os quais estavam:

Aprofundar a concertação político-diplomática nos domínios da paz, direitos humanos, ajuda ao desenvolvimento, comércio internacional e justiça social; assumir a responsabilidade comum na defesa dos valores e dos objectivos comuns no que concerne ao respeito e à segurança entre as nações (CPLP 2000, s/p).

Assim, na virada para o século XXI, em razão de demandas dos próprios Estados-membros e da conjuntura internacional, a CPLP avançou gradualmente em diversas áreas de cooperação, especialmente na Defesa. Com os resultados positivos da Cooperação Técnico-Militar bilateral de Portugal com os Palop, permitiu-se que se globalizasse aquela experiência partilhando-a entre os Estados-membros da CPLP, sendo que foram 
identificadas “ $[\ldots]$ novas áreas de cooperação a serem concretizadas numa perspectiva globalizante", figurando entre outras a “[ $\ldots]$ criação de um Centro de Análise Estratégica, com sede em Maputo, e núcleos em cada um dos países, fomentando-se uma maior e melhor consciencialização dos assuntos e matérias naqueles domínios [... $]{ }^{\prime},{ }^{9}$ bem como um Secretariado Permanente para os Assuntos de Defesa (SPAD) que seria acolhido em Lisboa, inserido na estrutura do Ministério da Defesa Nacional (Bernardino 2011a, 23).

\section{A COOPERAÇÃO DE DEFESA NO SEIO DA COMUNIDADE}

O Acordo sobre a Globalização da Cooperação Técnico-Militar, assinado pelos Ministros da Defesa dos Estados-membros em 25 de maio de 1999, na cidade da Praia, na II Reunião dos Ministros de Defesa Nacional dos Países de Língua Portuguesa, fez com que o componente de Defesa da Comunidade evoluísse para a consolidação dos seus Órgãos estruturantes, que têm mantido as iniciativas e atividades de caráter no quadro de uma cooperação estratégica estruturada a benefício de todos e em função do objetivo global de “[ $\ldots$.$] promover e facilitar a cooperação [...] sistemati-$ zando e clarificando as acções a empreender” (II Reunião 1999, 2).

Constituiu-se assim uma estrutura dinâmica com base nos seguintes órgãos estruturais: o Secretariado Permanente para os Assuntos de Defesa da CPLP (SPAD); as reuniões de CEMGFA; as reuniões de Diretores Nacionais de Política de Defesa; as reuniões de Ministros da Defesa da CPLP. Seria ainda criado, para funcionar como órgão do componente de Defesa da Comunidade para pesquisa, estudo e difusão de conhecimentos no domínio da estratégia com interesse para os objetivos globais dos Estados-membros, o Centro de Análise Estratégica da CPLP. Esta caracterização simples e pragmática contida, regra geral, nos normativos pertinentes, engloba, no entanto, uma multiplicidade de vetores que explicam não só a gênese, mas também o contexto em que se gerou a ideia da criação do Centro de Análise Estratégica da CPLP (CAE-CPLP),${ }^{10}$ bem como as legalidades e meios que assistiram à sua constituição. Outras iniciativas viriam a constituir-se e consolidar-se, designadamente os Exercícios Militares da série "Felino", ${ }^{11}$ a Conferência das Marinhas da CPLP e o Fórum de Saúde Militar.

Um aspecto que, no entanto, importa sublinhar neste componente são as normativas jurídico-políticas respectivas. Na verdade, o quadro jurídico-político dos órgãos e iniciativas acima referidas foi, em primeiro lugar, político e depois jurídico, na medida em que a prática e o seu exercício funcional careceram de imediato da legitimidade que só o nível político 
poderia fazer evoluir, por meio das Declarações finais da reunião de ministros recomendando as ações, bem como o direcionamento dos projetos a implementar, dando assim espaço para que cada uma das componentes ou níveis se articulassem entre si. E o quadro legal seria criado a posteriori, adequando-o à realidade conjuntural (Tavares and Bernardino 2011).

Essa representação legal foi aprovada pelos Ministros da Defesa na cidade da Praia, Cabo Verde, em 15 de setembro de 2006, por meio do Protocolo de Cooperação da CPLP no Domínio da Defesa e que é atualmente o documento-quadro com base no qual se rege a cooperação dos Países da CPLP nesta área. Estando já ratificado pela maioria dos Estadosmembros, não se encontra ainda em vigor, em virtude do seu Artigo $15^{\circ}$ estabelecer que aquele instrumento só “[ [...] entrará em vigor após a conclusão das formalidades legais, por parte de cada um dos Estados-membros (Protocolo 2006, s/p).

Contudo, sem perder de vista a natureza e o sentido para o qual foi criado o componente de Defesa da Comunidade, é no Artigo $4^{\circ}$ do Protocolo que se consubstanciam algumas linhas orientadoras, identificadas pela solidariedade entre os Estados-membros, a sensibilização das comunidades nacionais sobre a importância e o papel das Forças Armadas de cada país na defesa nacional, a partilha de informações, a formação militar, o prosseguimento dos Exercícios Militares "Felino", o reforço do controle e fiscalização dos espaços marítimos de cada um dos países e outros (como o fórum de saúde militar, a conferência de Marinhas, entre outros).

Apesar desta restrição legal, o articulado do Protocolo consagra e reconhece a necessidade de estreitar a cooperação no domínio da Defesa, sendo a paz, a segurança, a defesa e as boas relações políticas fatores primordiais para uma cooperação proativa, capaz de impulsionar o estreitamento dos laços de solidariedade entre cada um dos Estados-membros, projetando a Comunidade como uma organização de paz e de cooperação para a segurança, defesa e desenvolvimento. Isso significa que a CPLP tem vocação natural para ser parceira com outras organizações de ações e iniciativas conjuntas, em benefício e de interesse comum, como no caso da articulação com a Zopacas.

Das reflexões que surgiram sobre o Protocolo de Defesa resultou a recomendação dos Ministros da Defesa dos Estados-membros, na XV Reunião realizada em Lisboa, em maio de 2014, para que o componente de Defesa fosse dotado de um mecanismo de aspecto orientador e conceitual, capaz de dar sentido às iniciativas e à cooperação multilateral neste setor. Tratavase de elaborar um novo instrumento estruturante e também otimizador das sinergias da cooperação, que veio a ser designado por "Identidade da CPLP no Domínio da Defesa”, documento aprovado em 26 de maio de 2015, na 
cidade de São Tomé e endossado no Conselho Ordinário de Ministros da CPLP, realizado em Díli, em 24 de julho de 2015.

\section{A IDENTIDADE DA CPLP NO DOMÍNIO DA DEFESA}

Sobre a Identidade da CPLP no Domínio da Defesa, importa realçar o caráter inovador do documento, que não apenas reúne os conceitos fundamentais que envolvem a geopolítica e o entorno global dos Estadosmembros e, naturalmente, o Atlântico Sul e Norte, mas também pretende ser, do ponto de vista conceitual, a matriz fundamental do componente de Defesa. No vazio da existência de um conceito estratégico da CPLP, esse documento atenta para a importância das entidades coletivas, o que as une, o que as agrega, clarifica e orienta, sendo que no caso da Defesa são os interesses comuns neste setor que potencializam a cooperação em diferentes domínios, maximizando respostas comuns. E este princípio aplica-se, obviamente, ao universo da cooperação que se pretende para o segmento securitário dos Estados-membros no Atlântico Sul. Além disso, o documento identifica a matriz identitária da CPLP com base na Declaração Constitutiva e no atual Estatuto, apontando para o seu vértice fundamental, a cooperação, que comprova a hipótese de pesquisa apresentada.

Mas é evidente também a necessidade do enquadramento do contexto geoestratégico da Comunidade, o qual surge no ponto 2 do documento, onde se identificam algumas dinâmicas de insegurança e de segurança no espaço da lusofonia, resultando daí a exigência de abordagens e capacidades não só multissetoriais, mas também multilaterais. Também a inserção regional dos países da CPLP deve ser vista - e o documento incide nesse vetor - como uma mais-valia para a Comunidade, na medida em que impulsiona o aprofundamento da cooperação intra-CPLP.

O ponto 3 do documento identifica os valores comuns e interesses da CPLP no domínio da Defesa e, embora não o fazendo de uma forma exaustiva, o faz de forma clara e com base, uma vez mais, nos princípios gerais e objetivos da organização e em função da circunstância conjuntural, ou seja, vistos numa perspectiva dinâmica que envolve os valores designadamente culturais (caso da língua portuguesa), os valores humanistas e os da democracia e direitos humanos; vê, ainda, na concertação político-diplomática um instrumento fundamental para salvaguarda de interesses comuns, tal como na cooperação a alavanca fundamental do multilateralismo construtivo ou aberto. E por ser a cooperação (real e potencial) o principal referencial deste documento, o setor militar é referido como um dos melhores exemplos do espírito cooperativo e da interatividade humana e cultural. 
Destaca-se também a condição ribeirinha de todos os Estados-membros da CPLP e seu potencial geoestratégico (o mar), seus recursos e sua importância geopolítica no contexto global. $\mathrm{O}$ mar constitui, como vimos, a maior janela de oportunidades para a Comunidade:

[…] a condição ribeirinha/marítima de todos os Estados-membros da CPLP proporciona enormes vantagens que importa maximizar. $\mathrm{O}$ potencial estratégico do mar advém, entre outros, dos recursos estratégicos aí existentes, da sua importância geopolítica e estratégica no actual sistema internacional e da sua condição de factor de conexão e de desenvolvimento. Contudo, este enorme potencial, para ser maximizado, tem de ser devidamente explorado e protegido, pelo que a componente de defesa da CPLP tem um importante papel a desempenhar, onde o conhecimento situacional marítimo tem uma relevância acrescida, pois só assim se conseguem combater as ameaças que se materializam no ambiente marítimo [...] (Identidade 2015, 7. Grifo nosso).

Entretanto, a CPLP representa ainda no setor de Defesa um significativo potencial de dissuasão e que também deve ser desenvolvido no contexto securitário do Atlântico (Sul e Norte). Nesse aspecto, as diferentes e diversas iniciativas multilaterais, vistas à luz dos atuais desafios - e que também se encontram referenciados no texto sobre a Identidade da CPLP no Domínio da Defesa - assumem uma importância incontornável. Trata-se de cooperar nos domínios da formação (o que inclui educação, treinamento, capacitação e valorização das Forças); partilha de informação estratégica relativa às ameaças e aos desafios que se impõem aos Estados-membros com acesso comum a tecnologias e logísticas materiais que racionalizem custos e meios e, ao mesmo tempo, confiram capacidade de dissuasão e melhor defesa e segurança aos Estados perante os desafios e a rápida evolução tecnológica.

Relativamente aos pilares da Identidade da CPLP no domínio da Defesa, o tex to ainda sintetiza as linhas de ação da Comunidade nesta componente, assentando-os na questão dos valores e interesses comuns aos países da CPLP; na mobilização cooperativa; no aproveitamento das sinergias que advêm da idiossincrasia da organização no domínio da defesa; na ação do instrumento militar e da cooperação daí resultante (Identidade 2015, 8-9). Acredita-se, aqui, que o termo cooperar tende a se ampliar para partilhar conhecimento, formação, tecnologias, desafios e principalmente resposta às ameaças.

Entende-se que essa partilha corresponde à interatividade assumida como interoperabilidade, o que tende a ser o maior desafio que se impõe à CPLP no quadro de uma nova geopolítica, de uma nova geoeconomia e, 
por consequência, de uma nova geoestratégia que emerge como resposta premente a essas grandes ameaças globais - o terrorismo, expressamente o terrorismo militante, a pirataria e a guerra cibernética. $\mathrm{O}$ documento sobre a Identidade da CPLP no Domínio da Defesa termina com um apelo à vontade e empenho políticos para materialização de ações concretas. Com efeito, os ingredientes da cooperação integrada e interativa já se encontram expressos nos documentos referidos, afigurando-se necessário o seu aprofundamento e a efetiva operacionalização. Daí que se torna premente o empenho político das instâncias superiores da Comunidade para que a cooperação bi e multilateral se desenhe como resposta coerente e efetiva aos desafios da presente conjuntura e às ameaças globais que os Estadosmembros enfrentam, especialmente num momento em que se assiste a uma alteração global e profunda dos paradigmas securitários.

Com efeito, foi no contexto do sistema mundial pós-Guerra Fria que a CPLP emergiu tendo como matriz primacial e originária o patrimônio comum da Língua Portuguesa, a sua defesa, promoção e valoração no contexto global. Para Visentini (2019), os estudos da área de Relações Internacionais e Defesa buscam mensurar o poder mundial, identificando e classificando hierarquicamente as grandes e médias potências, e analisam a geografia do país, riquezas naturais, sua economia e o tamanho e estrutura de sua população, além da posição geopolítica, a estabilidade institucional, participação em organizações internacionais e dimensão e qualidade das Forças Armadas. Assim,

Sem dúvida, trata-se de elementos basilares, mas a forma como se articulam e sua importância relativa estão relacionadas com outros elementos qualitativos. Em primeiro lugar, há a evolução histórica (cada Estado-Nação tem suas características específicas), o nível de desenvolvimento social e econômico, o grau de articulação das elites no poder, a existência de um projeto nacional, as conexões internacionais e o posicionamento no sistema mundial, entre outros (Visentini 2019, 9-10. Grifo nosso).

Logo, o sistema mundial contemporâneo tem se caracterizado por uma reconfiguração intensa, passando de um conflito intersistêmico (Guerra Fria) à rearticulação do sistema capitalista, pós-Guerra Fria (Halliday 1999), momento histórico que tem sido marcado por intensa complexificação nas conjunturas internas e externas dos Estados. A bipolarização da Guerra Fria foi substituída pela unipolaridade momentânea na última década do século XX, agora posta em cheque com a nascente mutipolaridade, baseada na proliferação dos centros de poder e de decisão, Estados ou coalizões, em um período de clara crise e transição no sistema mundial, sem uma hegemonia inequívoca. A CPLP nasceu e se consolidou, de tal 
modo, em um ambiente internacional instável, incerto e transitório, mas também oportuno, para que os Estados-membros se aproximassem e associassem em torno de causas comuns.

Verifica-se ainda que os Estados (apesar da crise em que o EstadoNação se encontra) procuram novos fios condutores de coesão, proteção, defesa e promoção do desenvolvimento econômico e social através da sua integração e aprofundamento estruturante em organizações internacionais e regionais. Em geral, essas organizações têm contiguidade geográfica e são impulsionadoras de uma dinâmica de poderes multipolares e nas quais a palavra cooperação (numa perspectiva construtivista e até de soft power) é primacial e indutora dos novos centros de decisão.

Conceitualmente, os organismos internacionais representam uma associação voluntária entre os países, composta por meio de um tratado, com a previsão de aparelhamento institucional permanente, com personalidade jurídica distinta dos Estados que os constituem e vislumbra alcançar interesses comuns por meio da cooperação entre seus membros (Seitenfus 2012). O sistema mundial pós-Guerra Fria tem se caracterizado, também, por um aumento nesses processos de integração e cooperação (bi, tri e multilateral), sendo a CPLP resultante desse período. Para Rizzi e Cruzichi,

[…] A cooperação complementa a ação externa dos Estados, pois se apresenta como uma forma de criação e estreitamento de laços políticos, econômicos e culturais, além de conferir maior protagonismo internacional (instrumento de influência e credibilidade). De forma especial, a cooperação para o desenvolvimento, modalidade mais característica da CPLP, pressupõe um sistema mundial mais diversificado em termos de princípios, programas e práticas, resultado das diferentes experiências históricas (Rizzi and Cruzichi 2017, 37. Grifo nosso).

Desta forma, equaciona-se também a questão da segurança e defesa, ou seja, dos aspectos securitários dos Estados que são parte daquelas organizações e buscam respostas comuns para os desafios e ameaças transnacionais comuns. Gera-se assim a compreensão pela existência das alianças militares regionais, constituindo pactos de segurança e defesa que, embora limitados ao horizonte geográfico em que se inserem, também poderão atuar além dele sempre que esteja em causa o interesse e a proteção de qualquer dos membros que as compõem.

Em suma, a presente conjuntura de desafios e alteração de paradigmas no sistema mundial atual traz instabilidades e incertezas aos Estados, mas também oportunidades. Se, por um lado, os acontecimentos de 11 de setembro de 2001 resultaram de uma evolução que seria previsível ao olhar de alguns, por outro lado marcaram uma ruptura epistemológica com o 
que era por demais conhecido, e abriram uma rota de imprevisibilidade que acabaria por acentuar-se dramática e drasticamente no melting pot dos cenários a que hoje se assiste designadamente no Oriente Médio, Europa oriental, Extremo Oriente, no continente africano e no próprio continente americano.

A ideia de um poder unívoco que cede o lugar a uma multiplicidade de poderes, fundamentalmente regionais, e onde a multipolaridade das decisões é regra para uma cooperação frutífera, pode ir de encontro das intenções de terceiros, limitando geograficamente o que hoje já não parece ou não pode ser limitável, pela natureza das circunstâncias e o envolvimento global dos atores. Também compreende-se que as diferentes e diversas geopolíticas (sejam do mar, passando pela energia, pelos mercados, pela geoeconomia e pela projecção demográfica ou pelas ameaças transnacionais) estão a gerar novos matrizes que, no seu conjunto, serão determinantes para o futuro da própria humanidade.

\section{CONSIDERAÇÕES FINAIS}

Com estes elementos apresentados, parece essencial encarar-se a cooperação da CPLP no domínio da Defesa como vetor basilar de sua maturidade institucional, compreendida a maritimidade como seu elemento-chave. Em termos de conclusão, salienta-se que o Atlântico Sul tem sido historicamente uma região que funciona como um corredor aberto e pacífico. Mas, independentemente do desenvolvimento de capacidades dissuasoras, quer em termos de uma estratégia de defesa regional quer na sua operacionalização, não se pode desconectar o que se passa no norte do Atlântico sem avaliar as consequências para o sul. A crescente interdependência e o reforço da cooperação na segurança internacional têm levado ao cômputo direto das responsabilidades regionais.

Por isso, a CPLP não pode agir nem como bloco defensivo regional nem como estrutura global de defesa capaz de atuar em qualquer cenário (a isso a obrigam a Declaração Constitutiva, os seus Estatutos e nomeadamente o Protocolo da Cooperação da CPLP no Domínio da Defesa). Tem, no entanto, uma vocação universal de proteção humanitária que consubstancia a sua atuação à resposta aos pedidos de quaisquer dos parceiros em apoio a essas situações e de manutenção de paz no quadro restrito das missões da ONU ou sob sua égide. Aliás, em diversas destas missões de manutenção da paz das Nações Unidas têm participado forças de países da Comunidade, designadamente, Angola, Brasil, Cabo Verde, Moçambique e Portugal ${ }^{12}$.

Deve-se, ainda, realçar um aspecto do texto da Identidade da CPLP no Domínio de Defesa e que se relaciona à questão da interoperabilidade de 
forças, a qual poderá aplicar-se no contexto de uma arquitetura de segurança marítima para o Atlântico Sul: trata-se de um conceito que esteve sempre presente no seio da Comunidade, pelo menos, desde a institucionalização dos Exercícios "Felino" e, além disso, emerge dos objetivos específicos da cooperação no domínio da Defesa. Destaca-se, assim, a criação de uma plataforma de partilha de conhecimentos em matéria de defesa militar e de segurança marítima e na qual o Centro de Análise Estratégica tem um importante papel a desempenhar, aliado à política comum de cooperação para o desenvolvimento das capacidades militares internas com vista ao fortalecimento das Forças Armadas dos países da CPLP.

Nesse sentido, o desafio maior da Comunidade reside em saber lançar as pontes do diálogo e da cooperação construtiva e buscar redimensionar algumas deficiências nesse processo, que ainda prosseguem, como a) o limite regional da atuação da CPLP no domínio de concertação político-diplomática e no âmbito da Defesa e Segurança; b) a necessária transformação do arcabouço institucional (construção e publicação de documentos conjuntos entre os Chefes de Estado na área de Defesa e Segurança) em ações de interoperabilidade e práticas. Além destes, identifica-se que c) a cooperação bilateral ainda prevalece sobre a cooperação tri ou multilateral, em termos de Defesa e Segurança (especialmente tendo Brasil ou Portugal como atores-base dessa cooperação bilateral). Adicionalmente, no contexto africano, são evidentes d) as vulnerabilidades dos Palop no domínio da defesa e segurança, em especial no combate às novas ameaças (de efetivos, recursos, equipamentos, entre outros), embora tenha havido, nestes últimos anos, progressos significativos, nomeadamente em Angola e Cabo Verde (Military Balance 2020).

No contexto de minimizar tais dificuldades, a Comunidade tende a afirmar-se desenvolvendo capacidades no multilateralismo cooperativo, tornando-se cada vez mais uma alternativa num mundo global em que o elemento securitário assume maior importância e se relaciona com o soft power dos Estados que desenvolvem capacidades de liderança regional. $\mathrm{Na}$ ótica da presente pesquisa, essa deve ser a meta conceitual para confirmar a CPLP na área da Defesa, contribuindo para impulsionar capacidades nos Estados-membros nas áreas da formação, do partilhamento de informações e do desenvolvimento tecnológico, entre outros. Logo, pela análise da constituição da Comunidade e da realidade de seus Estados-membros, não faltam áreas e possibilidades onde essa interação bilateral e multilateral multidisciplinar podem ser prioritárias à luz da natureza de cada ameaça ou desafio.

Corroborando a hipótese de pesquisa relacionada ao problema inicialmente proposto, vislumbra-se que as motivações da visão geoestratégica 
da CPLP que resultaram na "Identidade da CPLP no Domínio da Defesa" são a valorização da concertação político-diplomática e da cooperação entre os Estados-membros, cuja ampliação das áreas de cooperação em 2002 (aí incluída a Defesa) complementam essa ideia-base da organização, ao fortalecer o aspecto estratégico desta no atual sistema mundial em torno dos mares/oceanos, geopolítica/geoestratégia e cooperação/parceria, classificando a Comunidade como marítima por excelência.

O processo de consolidação da Comunidade deve-se positiva e negativamente às circunstâncias de dispersão geográfica, à inserção regional de cada Estado-membro e aos respectivos compromissos, mas também às vicissitudes internas próprias de dinâmicas político-jurídicas, de desenvolvimento sócio-histórico e econômico, e de segurança e defesa globais. Essas variáveis podem resultar na perceção de um processo mais lento do que o esperado institucional e legalmente, pois não se pode perder de vista cada evolução histórica, o nível de desenvolvimento, o papel das elites nacionais, a existência ou não de um projeto nacional de cada Estado-membro e seu posicionamento no sistema mundial (Visentini 2019).

Identificam-se, assim, como linhas de ação e visão político-estratégica da CPLP na próxima década, a necessidade de aprofundar a cooperação em todos os setores (respeitadas as legislações e a soberania de cada Estadomembro), a contínua formação de quadros (academias civis e militares), a interação de diferentes níveis e estruturas de forma a criar uma teia integrada de ações cooperativas multilaterais (respeitando os diferentes níveis de desenvolvimento dos países integrantes), o incentivo às áreas da pesquisa científica e tecnológica e dos recursos marinhos (no sentido de contribuir para que cada Estado-membro diminua as faixas de dependências externas, ao passo que se encoraje o desenvolvimento sustentável), o gradual planejamento de recursos (geopolítica da energia e geoeconomia de mercados, por meio da partilha e de interesse comum em prol do desenvolvimento das comunidades) e o aprofundamento da concertação político-diplomática de forma a projetar a imagem da Comunidade no plano externo e nos foros internacionais.

O componente de Defesa dos países da CPLP tem, pois, desde a sua criação em 1999, contribuído de uma forma positiva e construtiva para a arquitetura geral de segurança e defesa da Comunidade. Uma análise mais aprofundada traz consigo um conjunto de iniciativas que, apesar de discretas, têm constituído passos importantes para a consolidação e a visibilidade, sobretudo na conjuntura da "Nova Visão Estratégica da CPLP", datada de 2014.

Por fim, a análise documental e bibliográfica realizada identificou que o trinômio da CPLP (mares/oceanos, geopolítica/geoestratégia e coope- 
ração/parceria) tem se consolidado como a principal plataforma de ação da organização, e isso se identifica no avanço das ações cooperativas na área de Defesa, tomando o caráter de Cooperação estratégica. É essencial a contribuição desse componente não só pelo caráter eminentemente construtivo e cooperativo, mas também pelo exemplo de coesão que os diferentes órgãos do componente de Defesa têm demonstrado, inclusive em circunstâncias por vezes complexas. Seguindo o princípio da cooperação bi e multilateral entre parceiros soberanos e iguais no nível decisor da Comunidade, entende-se que estes aspectos são evidenciados na Identidade da CPLP no Domínio da Defesa e orientam, inclusive, para uma cooperação atlântica aprofundada, pois o avanço da cooperação em Defesa complementa essa ideia-base da organização, ao fortalecer o aspecto estratégico da mesma no atual sistema mundial.

\section{REFERÊNCIAS}

II Reunião dos Ministros de Defesa Nacional dos Países de Língua Portuguesa. 1999. 24 e 25 de maio, Praia, Cabo Verde. https://www.cplp.org/Admin/Public/ DWSDownload.aspx? File $=\% 2$ FFiles $\% 2$ FFiler $\% 2$ Fcplp $\% 2$ Fredes $\% 2$ Fdefesa $\% 2 \mathrm{~F}$ DECLARACAODAPRAIA-II.pdf.

Alvaro, Nuno. 1993. Brasemb Praia [MSG OF $n^{o}$ O0414A], 04/09/1993, Praia [para] EXTERIORES/DAF-II, Brasília. 05 p.

Azevedo, Francisco. 2014. "A CPLP e o Atlântico Sul". Anais do VII ENABED. Brasília.

Azevedo, Francisco, and Luís Manuel Brás Bernardino. 2016. "Uma nova visão geoestratégica Na Comunidade de Países de Língua Portuguesa. A identidade da CPLP no Domínio da Defesa”. Revista PROELIUM X, no. 10: 21-42. Lisboa: Academia Militar. https://repositorio.iscte-iul.pt/bitstream/10071/10856/1/03_F.Azevedo _L.Bernardino.pdf.

Bernardino, Luís Manuel Brás. 2008. Estratégias de Intervenção em África. Uma década de segurança e defesa na Comunidade dos Países de Lingua Portuguesa. Lisboa: Editora Prefácio.

Bernardino, Luís Manuel Brás. 2011a. "A Segurança Marítima no seio da CPLP: Contributos para uma Estratégia nos Mares da Lusofonia". Revista Nação e Defesa, no. 128, 5a série: 41-65. Lisboa: Instituto de Defesa Nacional. https://comum. rcaap.pt/bitstream/10400.26/4744/1/NeD128_LuisManuelBrasBernardino.pdf.

Bernardino, Luís Manuel Brás, and José Santos Leal. 2011b. "A Arquitectura de Segurança e Defesa da Comunidade dos Países de Língua Portuguesa". IDN 
Cadernos, no. 6. Lisboa: Instituto de Defesa Nacional. https://www.idn.gov.pt/ publicacoes/cadernos/idncaderno_6.pdf.

Brasemb Praia. 1990. [OFC no OO122], 09/04/1990, Praia [para]EXTERIORES/ DAF-II, Brasília. 01 p. Relações Cabo Verde-Portugal.

Brasemb Praia. 1992. [OF C $n^{\circ}$ 0031-00112], 02/04/1992, Praia [para] EXTERIORES/DAF-II, Brasília. 04 p. Brasil e Portugal nos PALOP.

CPLP. 2006. Protocolo de Cooperação da Comunidade dos Países de Língua Portuguesa no Domínio da Defesa. https://cplp.defesa.pt/Normativos/20060915_ Protocolo\%20Cooperacao\%20CPLP\%20Dominio\%20Defesa.pdf.

CPLP. 2007. Estatutos da Comunidade dos Países de Língua Oficial Portuguesa (com revisões em São Tomé/2001, Brasília/2002, Luanda/2005, Bissau/2006 e Lisboa/2007). https://www.cplp.org/Files/Filer/Documentos\%20Essenciais/ Estatutos_CPLP_REVLISo7.pdf

2012. Normas para a Realização de Exercícios Militares da CPLP. https:// cplp.defesa.pt/Normativos/Normas_ExerciciosMilitares_CPLP.pdf.

. 2016. Protocolo que Altera o Protocolo de Cooperação da Comunidade dos Países de Língua Portuguesa no Domínio da Defesa. https://cplp.defesa.pt/ Normativos/20160520_Revisao\%20do\%20Protocolo\%20de\%20Cooperacao\%20 da\%20CPLP\%20no\%20Dominio\%20da\%20Defesa\%20(pendente).docx.

Gerhardt, Tatiana Engel, and Denise Tolfo Silveira (Org.). 2009. Métodos de pesquisa. Porto Alegre: Editora da UFRGS.

Halliday, Fred. 1999. Repensando as Relações Internacionais. Porto Alegre: Editora da Universidade/UFRGS.

Huntington, Samuel P. 1997. O Choque de Civilizações e a recomposição da Ordem Mundial. Rio de Janeiro: Editora Objetiva.

Identidade da CPLP no Domínio da Defesa. 2015. 26 de maio. https://cplp.defesa.pt/Normativos/20150526_IDENTIDADE\%20DA\%20CPLP\%20NO\%20 DOMINIO\%20DA\%20DEFESA.pdf.

MacQueen, Norrie. 2003. "A Community of Illusions? Portugal, the CPLP and Peacemaking in Guiné-Bissau". International Peacekeeping 10, no. 2: 1-26, DOI: 10.1080/714002450. https://www.academia.edu/1362444/A_Community_of_ Illusions_Portugal_the_CPLP_and_Peacemaking_in_Guin\%C3\%A9-Bissau. 
Military Balance. 2020. "The Military Balance 2020". International Institute for Strategic Studies (IISS) 120, cap. IX, 444-514.

Minayo, Maria Cecília. 1994. (Org.). Pesquisa social: Teoria, Método e criatividade. 19. ed. Rio de Janeiro: Vozes.

Mongiardim, Maria Regina de. 2014. A nova face da CPLP. https://www.academia.edu/10284452/A_Nova_face_da_CPLP.

Moreira, Adriano. 1993. Oceano Moreno. Revista Ciência e Trópico, vol. 21, 239-51. https://periodicos.fundaj.gov.br/CIC/article/view/543/383.

Nye, Joseph S. 2004. Soft Power: The means to success in World Politics. Foreign Affairs.

Protocolo de Cooperação da Comunidade dos Países de Língua Portuguesa no Domínio da Defesa. 2006. 15 de setembro. Praia, Cabo Verde.

Rizzi, Kamilla Raquel. 2014. O Grande Brasile os Pequenos Palop: a política externa brasileira para Cabo Verde, Guiné-Bissau e São Tomé e Príncipe. Porto Alegre: Leitura XXI/Cebrafrica.

Rizzi, Kamilla Raquel, and Isabella Cruzichi. 2017. "A CPLP como mecanismo de atuação do Brasil no Atlântico Sul: a ampliação da cooperação, os desafios e a possibilidade de liderança”. Revista Brasileira de Estudos Africanos 2, no. 4: 32-63. https://seer.ufrgs.br/rbea/article/view/79143/47055.

2018. "Os Exercícios Felino 2017 e a Cooperação em Defesa e Segurança na CPLP”. Boletim de Conjuntura Nerint 3, no. 8. Porto Alegre. https://www.ufrgs. $\mathrm{br} /$ nerint/wp-content/uploads/2018/04/Boletim-de-Conjuntura-v.3-n.8.pdf.

Seitenfus, Ricardo 2012. Manual das organizações internacionais. 5. ed. Porto Alegre: Livraria do Advogado.

Tavares, Rodrigo, and Luís Brás Bernardino. 2011. "Speaking the language of security: the Commonwealth, the Francophonie and the CPLP in conflict management in Africa". Conflict, Security \& Development 11, no. 5: 607-36, DOI: 10.1080/14678802.2011.641771. https://www.academia.edu/1432111/speaking_the_language_of_security_the_commonwealth_the_francophonie_and_the_ cplp_in_conflict_management_in_africa.

Visentini, Paulo Fagundes. 2019. "Eixos do poder mundial no século XXI: uma proposta analítica". Austral: Revista Brasileira de Estratégia e Relações Internacionais 8, no. 15: 9-25. https://seer.ufrgs.br/austral/. 


\section{NOTAS}

1. Como órgãos da Comunidade: a Conferência dos Chefes de Estado e Governo (previsão de se reunirem uma vez a cada dois anos); o Conselho de Ministros (uma vez por ano); o Comitê de Concertação Permanente (que se reúne ordinariamente, em Lisboa, uma vez por mês); e o Secretariado Executivo (principal órgão executivo da Comunidade, responsável pela implementação das deliberações emanadas dos demais órgãos). Em 2002, na $4^{a}$ Conferência de Chefes de Estado e Governo da CPLP, em Brasília, foram constituídas, ainda, a Reunião dos Pontos Focais da Cooperação, e as Reuniões Ministeriais. Como sede da CPLP, foi estabelecida a cidade de Lisboa, única capital que tinha presente embaixadas de todos os países signatários da Comunidade.

2. Estes valores tendem a aumentar, a partir das propostas de ampliação das Plataformas Continentais apresentadas na ONU.

3. Sete dos atuais nove Estados-membros de pleno direito da CPLP são países situados no Atlântico (Sul e Norte). No caso do Atlântico, já reconhecido como o mar por excelência da CPLP, e atenta às conhecidas ameaças transnacionais e os focos de instabilidade da região do Golfo da Guiné (com destaque para a pirataria, o tráfico de pessoas e estupefacientes, os fluxos migratórios ilegais, o tráfico de armas) bem como o respetivo impacto nas populações locais, a nova geopolítica dos recursos energéticos do Atlântico Sul alcança uma importância tal que induz a uma nova concertação das seguranças marítimas nacionais. Convém não esquecer que as ameaças no mar têm origem em terra e não no mar, o que obriga a um reforço da cooperação no domínio da segurança e da defesa no seio da Comunidade (Azevedo 2014).

4. Econômico, social, cultural, jurídico e técnico-científico.

5. Educação, saúde, ciência e tecnologia, defesa, agricultura, administração pública, comunicações, justiça, segurança pública, cultura, desporto e comunicação social.

6. Ver também a Resolução do Conselho de Ministros da CPLP, de 2 de Novembro de 2007, XII CM CPLP/PR.9/2007.

7. Bernardino $(2011,49-50)$ salienta ainda que “ $[\ldots]$ A estratégia da CPLP para os Oceanos rege-se por princípios e objectivos transversais aos demais vetores da cooperação no seio da comunidade, nomeadamente pelos princípios de igualdade soberana dos estados membros; do respeito pela integridade territorial; da promoção do desenvolvimento; e da promoção da cooperação mutuamente vantajosa. Entre os objectivos da comunidade, contam-se propósitos que podem igualmente ser relacionados com a presente estratégia, como a concertação político-diplomática entre Estados-membros, nomeadamente para o reforço da 
sua presença na cena internacional e a cooperação em vários domínios, como por exemplo, os da educação, ciência e tecnologia, defesa, administração pública, comunicações, justiça, segurança pública, cultura e desporto".

8. A CPLP conta com um histórico no domínio da observação eleitoral, tendo realizado missões de observação ao referendo sobre a autodeterminação de Timor-Leste, às eleições para a Assembleia Constituinte e às eleições presidenciais em Timor-Leste (1999, 2001 e 2002); às eleições autárquicas, presidenciais e legislativas em Moçambique (2003 e 2004); às eleições legislativas e presidenciais na Guiné-Bissau (2004 e 2005); às eleições legislativas e presidenciais em São Tomé e Príncipe (2006); às eleições parlamentares (2007) e eleições presidenciais em Timor-Leste (2007 e 2007); às eleições legislativas em Angola (2008); às eleições presidenciais na Guiné-Bissau (2010); às eleições presidenciais, legislativas e para as Assembleias Provinciais em Moçambique (2009); às eleições legislativas (2010) e presidenciais (2011) em São Tomé e Príncipe e às primeira e segunda voltas das eleições presidenciais em Timor-Leste (2012), bem como às legislativas de 2012. A CPLP enviou, também, uma MOE à primeira volta das eleições presidenciais na Guiné-Bissau (2012) e às Eleições Gerais em Angola, em 2012. Realizaram-se, ainda, as MOE-CPLP às eleições gerais na Guiné-Bissau (2014) e à segunda volta das eleições presidenciais (2014). Igualmente, a CPLP acompanhou com uma equipe as Eleições Presidenciais na Guiné Equatorial (2016) e enviou uma MOE às eleições em Angola (2017). Registraram-se, ainda, as MOECPLP às eleições gerais na Guiné-Bissau (2014), à segunda volta das eleições presidenciais (2014), às eleições presidenciais, legislativas e para as assembleias provinciais na República de Moçambique (2014) e às eleições legislativas, autárquicas e regionais em São Tomé e Príncipe (2014).

9. Estava dado o mote para a criação do Centro de Análise Estratégica da CPLP (CAE/CPLP).

10. O CAE/CPLP está instituído em sua sede em Maputo, Moçambique, e nos Núcleos Nacionais localizados em cada Estado-membro (Ministérios da Defesa). O CAE é o órgão responsável por promover pesquisas na área da estratégia considerando as necessidades dos países da Comunidade. Ele atua desenvolvendo estudos que viabilizem a atualização e aplicação de doutrinas e procedimentos, no domínio da defesa, de interesse comum dos países. O Centro também criou um arquivo divulgando trabalhos a respeito de suas atividades; outro objetivo importante do CAE/CPLP é habilitar, por meio do conteúdo 
obtido a partir de suas pesquisas, entre os Estados-membros, a tomada de posições concertadas nos diversos fóruns internacionais (Estatuto CAE/CPLP, 2015).

11. Os Exercícios militares iniciaram no ano 2000, sendo os dois primeiros realizados em Portugal (o primeiro foi organizado por Portugal), no formato Forças no Terreno (FT), com o objetivo de treinar a atuação conjunta de forças dos países que constituíam a Comunidade. A partir de 2004, deu-se início à rotatividade e, atualmente, os Exercícios são executados com uma periodicidade anual, alternando a versão Exercício na Carta (EC) com a de Forças no Terreno (FT) - no ano em que se realiza na modalidade EC, utiliza-se o cenário a ser aplicado no formato FT do ano seguinte. Segundo normas da CPLP, o Brasil, Angola e Portugal sediam os exercícios do tipo FT e as demais nações, as operações em Carta. A série de Exercícios "Felino" foi criada para regularizar a realização de exercícios militares conjuntos e combinados, incentivando a interoperabilidade das Forças Armadas dos Estados-membros da CPLP, bem como o treinamento para seu uso em Operações de Paz e de Ajuda Humanitária, no quadro da CPLP ou das organizações regionais, sob a égide da Organização das Nações Unidas (Rizzi and Cruzichi 2018,6).

12. Só assim fazem sentido os Exercícios "Felino", as iniciativas das Marinhas da CPLP, o quadro normativo da Estratégia da CPLP para os Oceanos, a Identidade da CPLP no Domínio da Defesa, e fará igualmente sentido a Nova Visão Estratégica da CPLP. 
A "IDENTIDADE DA CPLP NO DOMÍNIO DA DEFESA":

UMA VISÃO AMPLIADA PARA A COOPERAÇÃO EM DEFESA

\section{RESUMO}

A principal ideia referente à Comunidade dos Países de Língua Portuguesa (CPLP) é a de ser uma organização internacional que partilha uma matriz comum histórico-cultural-linguística, apostando no desenvolvimento da cultura e da língua portuguesa, e que vem se afirmando no sistema mundial pela adoção de uma inovadora e pragmática visão político-estratégica para a cooperação entre Estados-membros. Visão esta que na área da Defesa torna-se bem evidente com os seguintes conceitos-chave: mares/oceanos; geopolítica/geoestratégia e cooperação/parceria. A presente pesquisa reflete sobre quais as motivações dessa visão geoestratégica da CPLP que resultaram no documento intitulado "Identidade da CPLP no Domínio da Defesa”. Metodologicamente, a pesquisa utiliza a abordagem qualitativa com o método hipotético-dedutivo, classificando-se como descritivo-explicativa aos objetivos. Quanto aos procedimentos, utilizou-se a revisão bibliográfica e análise documental de fontes primárias e secundárias.

Palavras-chave: CPLP; Cooperação Estratégica; Defesa; Concertação PolíticoDiplomática.

\section{ABSTRACT}

The main idea regarding the Community of Portuguese Speaking Countries (CPLP) is to be an international organization that shares a common historical-cultural-linguistic matrix, focusing on the development of Portuguese culture and language, and that has been asserting itself in the world system by the adoption of an innovative and pragmatic political-strategic vision for cooperation between Member States. This view that in the area of Defense becomes evident with the key concepts: seas/ oceans; geopolitics/geostrategy and cooperation/partnership. The present research ponders about the motivations of this geostrategic vision of CPLP that resulted in the document entitled "CPLP Identity in the Defense Domain”. Methodologically, the research uses the qualitative approach with the hypothetical-deductive method, classifying it as descriptive-explanatory to goals. As for the procedures, bibliographic review and documentary analysis of primary and secondary sources were used.

Keywords: CPLP; Strategic Cooperation; Defense; Political-Diplomatic Consultation.

Recebido em 04/02/2020. Aceito para publicação em 13/05/2020. 